\title{
OPG/RANK/RANKL signaling system and its significance in nephrology
}

\author{
Katarzyna Klejna, Beata Naumnik, Katarzyna Gąsowska, Michał Myśliwiec
}

Department of Nephrology and Transplantation with Dialysis Unit, Medical University of Białystok, Białystok, Poland

\begin{abstract}
Recent years brought the discovery of new members of TNF receptor superfamily - osteoprotegerin/receptor activator of nuclear factor- $\kappa \mathrm{B}$ and its ligand (OPG/RANK/RANKL) system as regulator of bone remodeling. Further studies showed its involvement in control of vascular and immune system. Animal studies' results confirm the OPG/RANK/RANKL role in pathogenesis of vascular calcifications and osteoporosis. Human studies, especially in patients with chronic kidney disease (CKD), have brought many conflicting data. Understanding of exact contribution of each molecule creating this axis may be crucial for diagnosis and treatment of CKD complications involving renal osteodystrophy and vascular calcification. In this review we try to summarize recent knowledge and OPG/RANK/RANKL role in patient with chronic kidney diseases.
\end{abstract}

Key words: osteoprotegerin (OPG), receptor activator of nuclear factor- $\mathrm{B}$ (RANK), receptor activator of nuclear factor- $\mathrm{KB}$ ligand (RANKL), chronic kidney disease, vascular calcification, renal osteodystrophy

\section{Introduction}

Bone is continuously renewed by the process of remodeling in which "old bone" is removed from the surfaces of trabecular and cortical bone by osteoclasts and subsequently replaced by a new bone laid down by osteoblasts. Regulation of bone reconstruction process was a mystery for many years. In early 1980s Rodan and Martin postulated that osteoclasts formation and activity are regulated by osteoblasts [1]. In 1990s osteoprotegerin/receptor activator of nuclear factor- $\mathrm{KB}$ and its ligand (OPG/RANK/ RANKL) signaling system was finally identified. Currently, we know that this triad is essential not only for pathophysiology of bone remodeling but is also involved in immune and vascular control systems.

Metabolic bone dysfunction in chronic kidney disease (CKD) is a result of vitamin $\mathrm{D}$ and parathyroid system disorder. With the decline in glomerular filtration rate (GFR) and phosphate retention, hyperphosphatemia and impaired production of vitamin D occur.

Correspondence: K. Klejna, Dept. of Nephrology and Transplantation with Dialysis Unit, Medical University of Białystok, Żurawia 14 St, 15-540 Białystok, Poland; e-mail: k-julia@o2.pl
It leads to decrease of serum ionized calcium concentration. Decreased concentration of ionized calcium and calcitriol together with hyperphosphatemia stimulate parathormon (PTH) secretion. Constant stimulation of PTH secretion leads to hyperplasia of parathyroid glands and finally causes secondary hyperparathyroidism [2]. In end stage renal disease (ESRD) a higher PTH concentrations are required to maintain homeostasis of bone metabolism.

In renal osteodystrophy (ROD) remodeling may be up or down regulated which results in high (predominant hyperparathyroid bone disease and mixed uremic osteodystrophy) or low (adynamic bone disease and osteomalacia) turnover renal osteopathy. Correct ROD diagnosis is crucial for adequate treatment. The only way to distinguish unquestionably among different types of ROD is bone biopsy which is invasive and painful procedure. Therefore researches are looking for noninvasive diagnostic methods and trying to use biochemical markers of bone turnover.

\section{Osteoprotegerin (OPG)}

Osteoprotegerin, called "bone protector", belongs to TNF receptor's family, is a soluble glycoprotein (has 
no transmembrane domain) consisting of 380 aminoacids and seven domains. It is expressed in many types of cells like osteoblasts, heart, kidney, liver, spleen and bone marrow [3]. In bone tissue OPG is produced by osteoblasts, while in the vessels by endothelial (EC) and vascular smooth muscle (VSMCs) cells.

Molecules that up regulate OPG synthesis by osteoblasts are: IL-1 $\alpha$, IL-6, IL-11, IL-17, IL-18, TNF- $\alpha$, TNF- $\beta$, bone morphogenic protein (BMP-2), calcium, vitamin D3, estrogens, angiotensin II and platelet derived growth factor (PDGF) [4]. Next, PTH, glucocorticoids, prostaglandin E2, immunosuppressant drugs, peroxisome proliferators activated receptor (PPAR- $\gamma$ ). and basic fibroblast growth factor (bFGF) down regulate OPG production [4].

OPG has been identified as a cytokine that increases the mineral density and volume of bone tissue by decreasing the number of active osteoclasts. Over expression of OPG in transgenic mice results in severe osteopetrosis, characterized by increased bone turnover and an inhibition of osteoclastogenesis [5]. OPG-deficient mice develop osteoporosis because of an unopposed actions of RANKL to stimulate osteoclastic cells formation, activity and survival [6]. Based on the presence of renal artery and aortic medial calcification in osteoprotegerin deficient mice, OPG also appears to protect large vessels from medial calcification [7].

Osteoprotegerin functionally acts as a decoy receptor that blocks interaction between the receptor activator of nuclear factor- $\mathrm{KB}$ (RANK) and its ligand (RANKL), thereby inhibits osteoclasts' differentiation as well as theirs activity and prevents bone loss. OPG has also been shown to bind TNF-related apoptosis inducing ligand (TRAIL/Apo2L) - another member of TNF ligand super family. In this way it inhibits the induction of human osteoclasts apoptosis by preventing TRAIL from binding to its receptors $[8,9]$. OPG is also involved in efficient antibody response and B-cell maturation [10].

In endothelial cells OPG is physically associated with von Willebrand factor (vWF), glycoprotein involved in primary hemostasis and also important marker of endothelial injury. In response to inflammatory stimuli OPG and vWF are rapidly secreted that can proof OPG role in vascular injury, inflammation and hemostasis [11]. Because OPG is able to bind vWF reductase, thrombospondin-1 (TSP-1), it may also play a role in regulation of thrombus formation [11].

\section{Receptor activator of nuclear factor $-\kappa B$ (RANK)}

RANK, another member of TNF receptor superfamily, is a homotrimeric transmembrane protein consisting of 616 aminoacids. It is expressed on osteoclasts' precur- sors, mature osteoclasts, dendritic cells, mammary glands, and some cancer cells including breast and prostate cancers - tumors with very high bone metastatic potential [3]. After binding its ligand - RANKL, RANK assembles into functional trimeric receptor and this trimerisation is required to generate multiple intracellular signals that regulate cell differentiation, function and survival, among the others - mature and functional osteoclasts.

\section{Receptor activator of nuclear factor- $\mathrm{k} B$ ligand (RANKL)}

RANKL, similar to OPG, belongs to TNF super family. It is a homotrimeric glycoprotein consisting of 316 aminoacids which exists as a transmembrane protein and in soluble form. Most of the factors stimulated osteoclasts' formation and activity induce RANKL expression by osteoblastic and stromal cells. RANKL is also expressed in activated T-lymphocytes, lymph nodes, thymus, mammary glands, lungs, spleen and bone marrow [3]. It is considered to be a dendritic-cellstimulation agent that was a reason for suggesting its first name TRANCE - TNF-related activation-induced cytokine. RANKL acts as a survival factor for dendritic cells and for mature T-cells through regulating their proliferation [12].

While OPG presents as a soluble bone protector, RANKL is considered to be stimulator of bone resorption. It is a pro-resorptive factor because of induction of osteoclasts' differentiation and activation of mature osteoclasts. In contrast to OPG deficient mice, RANKL transgenic mice exhibit a marked osteoporosis while mice disrupted for RANKL are strongly osteopetrotic with a total absence of mature osteoclasts [13].

RANKL production is stimulated by IL-1, IL-6, IL11 , IL-17, TNF- $\alpha$, vitamin D3, calcium, PTH, glucocorticoids, prostaglandin E2 and immunosuppressive drugs. Its production is down regulated by TGF- $\beta$ [4].

RANKL stimulates RANK and in presence of stimulating factors (e.g. M-CSF) may lead to initiation of osteoclastogenesis - development of multinucleated bone-resorptive osteoclasts from monocytes' precursors. It also promotes the resorptive activity and survival of mature osteoclasts. RANKL is assumed to stimulate osteogenic differentiation and calcification of vascular smooth muscle cells as well [14].

\section{OPG/RANK/RANKL interaction}

RANKL acts through its receptor RANK. After binding, RANKL induces intracellular signals that regulate differentiation, function and survival of osteoclasts. OPG secreted by osteoblastic lineage cells, acts as a decoy receptor binding RANKL and preventing RANKL interaction with RANK. This results in inhibition of 
osteoclastic differentiation and in consequence inhibits bone resorption. Additionally OPG modulate RANKL half-life, and in turn, RANKL controls the bioavailability of OPG, its internalization and degradation [15]. Because OPG directly counter all RANKL-mediated actions through RANK, RANKL/OPG ratio is an important determinant of bone mass and skeleton integrity. Imbalances in the RANKL/OPG ratio or RANK signaling underlie the pathology of many skeletal disorders with excessive bone loss, excessive bone formation, or diseases with disordered bone remodeling [16]. It also has been shown that this system is involved in regulation of immune system and development of vascular calcification [15].

\section{OPG/RANK/RANKL role in pathogenesis of skeletal diseases}

Nowadays, many OPG/RANK/RANKL-mediated diseases are known. Among others, there are metabolic bone diseases, like postmenopausal osteoporosis due to estrogen deficiency as well as sporadic Paget disease - both with enhanced RANKL expression and increased RANK responsiveness of osteoclasts [17]. Glucocorticoid induced osteoporosis and hyperparathyroidism proceed with up regulation of RANKL expression and inhibition of OPG secretion [17]. Immune-mediated bone diseases, presented as periodontal infection or rheumatoid arthritis, are associated with up regulation of RANKL expression by activated $T$ cells and synoviocytes [17].

In malignant diseases, such as myeloma, osteolytic bone metastases of prostate and breast cancer, we can observe enhanced expression of RANKL by tumor cells and tumor-inducted increase of the RANKL/OPG ratio in bone microenvironment. Additionally, especially in myeloma there is a sequestration and lysosomal degradation of OPG by tumor cells [17].

Inherited skeletal diseases, like familial Paget disease and expansive skeletal hyperphosphatasia, are caused by mutations in gene encoding the signal peptide RANK. Next, juvenile Paget disease is caused by mutation in gene encoding OPG [17].

Understanding the role of OPG/RANK/RANKL system in pathogenesis of diseases stated above led to development of new therapeutic strategies including e.g. a monoclonal antibody to RANKL, as denosumab, for the postmenopausal osteoporosis treatment [18].

\section{Role of OPG/RANK/RANKL system in immunology}

A cross-talk between bone metabolism and the immune response is called osteoimmunology. The OPG/RANK/RANKL triad exerts activities on different parts of immune system.
RANKL and OPG are essential for dendritic cells functions, lymph node organogenesis, and lymphocyte development [19]. There are many examples for involvement this triad in immunology which comes from experimental animal studies. OPG deficient mice exhibit impaired thymocyte development and presented disturbance in B-cell maturation and antibody response [10]. Mice with a disrupted RANKL gene show a lack of all lymph node organogenesis, normal splenic and Peyer's patches organization, and also impaired thymocyte development. RANK knock-out mice also lacked lymph nodes and produced defective $\mathrm{B}$ and $\mathrm{T}$ lymphocyte maturation while they exhibited normal thymic development. It is possible that RANKL expressed by thymic epithelial cells may be responsible for the development and maturation of RANK-positive lymphocytes. Moreover, RANKL behaves as a chemotactic factor for monocytes through its binding to membrane RANK. OPG also can modulate the migration of monocytes [15].

\section{Role of OPG/RANK/RANKL system in vascular remodeling}

Vascular calcification often occurs with advancing age, atherosclerosis, end-stage renal disease, diabetes mellitus and now has been suggested to be related to ossification. It is an active process which involves inflammatory cytokines. Many proteins responsible for bone formation have been identified on the arterial wall. Dendritic cells, monocytes, smooth muscle cells are also crucial for calcium deposition in lesions because of their capability to differentiate into osteoblasts-like and osteoclasts-like cells [20]. Medial calcification occurs independently of atherosclerosis and is observed in e.g. hypervitaminosis D and ESRD. Intimal calcification was observed almost exclusively in atherosclerotic plaques.

\section{OPG and vascular remodeling}

OPG seems to be basic ligand between bone tissue and the vascular system [21]. It protects large blood vessels from medial calcification. It has been shown that the onset of arterial calcification in OPG deficient mice can be prevented by transgenic OPG delivered from mid gestation through adulthood. Interestingly, postnatal intravenous injection of recombinant OPG had no effect on the presence of vascular calcification. It suggests that OPG cannot reverse the calcification process once it had occurred [22].

Similarly, rat models showed that OPG administration prevents calcification induced by warfarin or high doses of vitamin D but could not reverse this phenomenon once the mineralization process had occurred [23]. OPG can also limit calcification of atherosclerotic plaques. [24] 
Although most animal studies support a protective role of OPG in vasculature, human studies have paradoxically shown a positive association between serum OPG levels and clinical cardiovascular disease. Elevation of OPG seems to be in contrast to its protective role upon arterial wall. For example, some clinical reports show correlation between higher levels of OPG and artery disease, vascular calcification, advanced atherosclerosis, coronary disease, myocardial infarction, heart failure, diabetic complications, abdominal aortic aneurysm, peripheral arterial disease, symptomatic carotid artery stenosis and cardiovascular mortality $[4,14]$. Statistical analysis of serum OPG levels in vivo has proven serum OPG as an independent prognostic factor for cardiovascular disease [25].

Whether elevated OPG is simply a marker of vascular damage, actively mediates disease progression or represents a mechanism aimed to limit vascular disease remind not clear [26]. OPG may act as a protective factor for vascular disease and increase in OPG may be compensatory as a response to the progression of vascular calcification.

\section{RANKL and vascular remodeling}

Endothelial cells and VSMCs normally produce OPG. RANKL and RANK are not detected in normal vasculature [22]. It is already known that small amount of RANKL have been detected in initial stages of atherosclerosis, whereas in advanced lesions as calcified vessels and valves, OPG remained constant or decreased slightly, while the expression of RANKL and RANK was simultaneously increased [27].

It has been shown that RANKL, which is up regulated in vulnerable atherosclerotic lesions prone to rupture, may contribute in the transition from stable to unstable atherosclerotic plaque because of its ability to promote monocyte/macrophage chemotaxis and matrix degeneration [28]. Moreover, RANKL stimulates osteogenic differentiation and calcification of VSMCs $[14,16]$. There are some studies that prove association between RANKL and cardiovascular diseases. In large epidemiological study of Kiechl et al., higher levels of RANKL significantly predicted the risk of cardiovascular disease. This study also support concept that RANKL contributes to the destabilization of existed plaques [29].

\section{The significance of OPG/RANK/RANKL axis in nephrology}

The role of OPG/RANKL/RANKL system in chronic kidney disease complications, especially in permanently dialysis patients, has been not fully understood yet. Uremia induces a derangement in bone and mineral homeostasis known as renal osteodystrophy. Patients with chronic kidney disease, regarding advanced age, postmenopausal age, glucocorticoid treatment or chronic heparin usage in $\mathrm{HD}$, are at risk for developing osteoporosis and its comorbidities. Additionally there is a relationship between ROD and vascular calcification [30].

\section{OPG/RANK/RANKL system in renal osteodystrophy}

Many humoral factors are involved in the ROD development. The OPG/RANK/RANKL cytokine system appears to mediate the effect of many bone turnover factors, contributing to the pathogenesis of renal bone disease [2]. There were conducted studies to distinguish different types of ROD by measuring OPG levels. Coen et al. have found an inverse correlation between serum OPG levels and histomorphometric parameters of bone resorption what suggests, that higher levels of serum OPG may be related to lower bone turnover [31]. In Haas et al. study, OPG was significantly reduced in patients on maintenance hemodialysis (HD) therapy with high turnover disease when compared with low turnover [32]. Whether elevated serum OPG is connected with low or high bone turnover in HD patients remind unclear and require further investigations [33].

\section{OPG/RANK/RANKL system in ESRD}

Exposure of osteoblasts to PTH in hyperparathyroidism increases the expression of RANKL and decrease the expression of OPG, thus decreased concentration of OPG should be expected in any type of hyperparathyroidism. In vitro study conducted by Huang confirmed that PTH significantly up regulates RANKL m-RNA of bone marrow stromal osteoblasts and inhibits OPG gene expression at all stages of osteoblasts' differentiation [34].

Studies of OPG and RANKL levels in CKD and hemodialysis patients have shown contradictory results. OPG concentrations are reported to be higher in HD patients [35-39], whereas RANKL level can be higher [39,40], lower [36] or within normal range [41] compared to healthy individuals. Kazama showed that serum OPG levels in uremic patients were elevated and independent of their serum PTH levels, what suggested the circulating OPG to be an independent factor affecting bone metabolism in uremic patients [42]. Avbersek-Luznik et al. study showed that serum OPG levels were 6,4-fold higher in dialysis patients compared to controls, and was depended on PTH concentration [38]. Another research by Avbersek-Luznik et al. support hypothesis that PTH increases bone resorbtion in HD patients through stimulating RANKL 
synthesis [40]. Conversely, in Doumouchtsis study, the average serum concentration of sRANKL was lower in patients on HD than in age-matched healthy controls [36] .

In predialysis patients, serum OPG increased progressively with reduction in creatinine clearance. In dialysis patients OPG further increased, according to Kazama study 3-fold [43]. This concentration corresponded to the OPG level that would inhibit $50 \%$ of osteoclasts formation in vitro [44]. Among HD patients, serum OPG level increased significantly with aging and with longer duration of HD. Increase in OPG with longer duration of HD may be related to stimulation by uremia, hemodialysis procedure itself, and drugs [36]. Kazamo et al reported that OPG is not removed through the polysulfon hemodialysis membrane. In physiological condition, OPG monomer seems unlikely to be eliminated through glomerular membrane filtration because of its molecule size (60 $\mathrm{kDa}$ ). Authors concluded that kidneys probably play a key role not only in OPG elimination but also in its metabolism before the renal clearance [43]. It may be supported by finding that elevated OPG level returns to normal after kidney transplantation [45].

To conclude, OPG increment might protect bone against its intensive loss in chronically HD patients by its accumulation in uremia and reducing of RANKL level. This may be skeleton protective mechanism to compensate any perturbations in bone turnover in renal failure [36].

\section{Osteoporosis in ESRD}

Patient with chronic kidney disease is also at risk for development of osteoporosis. Osteoporosis is present in both low and high-bone turnover states and bone loss begins much earlier in chronically HD patients than in general population [30]. In Baretto study, OPG/RANKL ratio in osteoporosis group was higher and OPG as well as OPG/RANKL ratio correlated negatively with trabecular bone volume (BV/TV). As mentioned above this could be protective mechanism that limits the bone loss by decreasing bone resorption [30].

Doumouchtis et al. evaluated clinical and biochemical correlations of bone mineral density (BMD) measurements in chronic haemodialyzed patients. The highest OPG levels were in the lowest T-score that means osteoporotic tertile and were higher than in osteopenic and normal tertiles. HD patients with low BMD of femoral neck demonstrated higher OPG levels than patients with normal BMD [2]. This study showed that patients on dialysis for longer period had BMD below normal range [2].

In pathogenesis of osteoporosis in HD patients, usage of heparin during the dialysis seems to play significant role. Heparin is a member of glycosaminoglycan family which shows anticoagulant activity by binding to antithrombin thus is used for anticoagulant therapy. One of adverse effects during heparin treatment reduction in bone density and development of osteoporosis, is related to OPG/RANKL/RANK system. Heparin binds to OPG (C-terminal domain) and inhibits the interaction between OPG and RANKL thus enhances osteoclastic bone resorption [46]. Lowmolecular weight heparins (LMWHs) cause less osteoporosis than unfractionated heparin (UFH) [47], follows their lower inhibitory effect to OPG than standard heparin [46].

These findings should be collated with Vic et al. study, showing that UFH and high doses of LMWHs increase plasma OPG concentrations. Intravenous administration of UFH is superior to subcutaneous injection of LMWHs in OPG mobilization into the circulation. Researchers concluded that UFH has higher affinity for OPG than LMWHs. They speculated that UFH induces osteoporosis either by attracting OPG to the vascular compartment or by impairing its function in the bone microenvironment [48]. So still, further studies are required to investigate exact role of OPG/RANK/RANKL system in heparin-induced osteoporosis.

\section{CVD risk and vascular calcifications in CKD patients}

Patients with chronic kidney disease are at high risk for vascular calcification because of multiple risk factors that induce transdifferentiation of VSMCs into a chondrocyte or osteoblast-like cell. Among factors implicating in that phenomenon are: high content of calcium and phosphorus caused by abnormal bone metabolism, low levels of circulating and locally produced inhibitors, impaired renal function and current therapies [49].

Chronic kidney disease patients have two to five times more coronary artery calcification than healthy age-match individuals and vascular calcification is an important prognostic marker of cardiovascular disease in CKD patients [50]. Cardiovascular disease (CVD) is responsible for about $50 \%$ of deaths among ESRD patients. In chronically HD patients prevalence of coronary artery disease is $40 \%$ [30]. Except of traditional risk factors, like hypertension, diabetes or dyslipidemia, there are additional factors related to uremia and dialysis treatment, like hyperhomocysteinemia, increased change in mineral metabolism, chronic inflammation or oxidative stress [30].

In CKD patients there is a direct correlation between vascular calcification, cardiovascular risk and OPG level, just like in patients without chronic kidney disease. Chronically dialyzed children with calcification have higher OPG level than those without this 
complication [51]. Nitta et al. concluded that fast progression of vascular calcification in HD patients was associated with higher OPG concentration [52]. In Speer et al. study, authors showed that in HD patients OPG is strongly related to carotid-femoral pulse wave velocity (PWV), and that OPG related cardiovascular risk is partly mediated by increased PWV [53].

Elevated OPG levels (especially in patients with high CRP concentration) in Morena et al. study, predicted all-cause and cardiovascular mortality. In the same study, low levels of sRANKL were associated with a protective effect for all-cause mortality [54] which is in accordance to Kiechl et al. study [29] but inconsistent with Schopppet et al. [55] who have shown, that low RANKL levels were associated with higher vascular risk. Only Yokoyama has reported low OPG levels as a predictor of poor prognosis in Japanese diabetic hemodialysis patients [56].

\section{Summary}

Discovery of OPG/RANK/RANKL system was major breakthrough in understanding of regulation of bone remodeling. Another achievement was finding involvement in control of immune and vascular systems. Animal studies' results are clear and dissolving doubts about role of axis in pathogenesis of vascular calcifications and osteoporosis. Researches in humans, especially in CKD patients, brought many conflicting data. We rather presume than state so several further studies are required to elucidate exact contribution of each OPG/RANK/RANKL molecule in development of CKD complications.

\section{References}

[ 1] Rodan GA, Martin TJ. Role of osteoblasts in hormonal control of bone resorption--a hypothesis. Calcif Tissue Int. 1981; 33:349-351.

[2] Doumouchtsis KK, Kostakis AI, Doumouchtsis SK, Tziamalis MP, Stathakis CP, Diamanti-Kandarakis E, Dimitroulis $\mathrm{D}$, Perrea DN. Associations between osteoprotegerin and femoral neck BMD in hemodialysis patients. J Bone Miner Metab. 2008;26:66-72.

[3] Boyce BF, Xing L. Functions of RANKL/RANK/OPG in bone modeling and remodeling. Arch Biochem Biophys. 2008; 473:139-146.

[4] Papadopouli AE, Klonaris CN, Theocharis SE. Role of $\mathrm{OPG} / \mathrm{RANKL} / \mathrm{RANK}$ axis on the vasculature. Histol Histopathol. 2008;23:497-506.

[5] Simonet WS, Lacey DL, Dunstan CR, Kelley M, Chang MS, Luthy R, Nguyen HQ, Wooden S, Bennett L, Boone T, Shimamoto G, DeRose M, Elliott R, Colombero A, Tan HL, Trail G, Sullivan J, Davy E, Bucay N, Renshaw-Gegg L, Hughes TM, Hill D, Pattison W, Campbell P, Sander S, Van G, Tarpley J, Derby P, Lee R, Boyle WJ. Osteoprotegerin: a novel secreted protein involved in the regulation of bone density. Cell. 1997;89:309-319.

[6] Mizuno A, Amizuka N, Irie K, Murakami A, Fujise N, Kanno T, Sato Y, Nakagawa N, Yasuda H, Mochizuki S, Gomibuchi
T, Yano K, Shima N, Washida N, Tsuda E, Morinaga T, Higashio K, Ozawa H. Severe osteoporosis in mice lacking osteoclastogenesis inhibitory factor/osteoprotegerin. Biochem Biophys Res Commun. 1998;247:610-615.

[ 7] Bucay N, Sarosi I, Dunstan CR, Morony S, Tarpley J, Capparelli C, Scully S, Tan HL, Xu W, Lacey DL, Boyle WJ, Simonet WS. osteoprotegerin-deficient mice develop early onset osteoporosis and arterial calcification. Genes Dev. 1998; $12: 1260-1268$.

[ 8] Emery JG, McDonnell P, Burke MB, Deen KC, Lyn S, Silverman C, Dul E, Appelbaum ER, Eichman C, DiPrinzio R, Dodds RA, James IE, Rosenberg M, Lee JC, Young PR. Osteoprotegerin is a receptor for the cytotoxic ligand TRAIL. J Biol Chem. 1998;273:14363-14367.

[ 9] Chamoux E, Houde N, L'Eriger K, Roux S. Osteoprotegerin decreases human osteoclast apoptosis by inhibiting the TRAIL pathway. J Cell Physiol. 2008;216:536-542.

[10] Yun TJ, Tallquist MD, Aicher A, Rafferty KL, Marshall AJ, Moon JJ, Ewings ME, Mohaupt M, Herring SW, Clark EA. Osteoprotegerin, a crucial regulator of bone metabolism, also regulates $\mathrm{B}$ cell development and function. J Immunol. 2001;166:1482-1491.

[11] Zannettino AC, Holding CA, Diamond P, Atkins GJ, Kostakis P, Farrugia A, Gamble J, To LB, Findlay DM, Haynes DR. Osteoprotegerin (OPG) is localized to the Weibel-Palade bodies of human vascular endothelial cells and is physically associated with von Willebrand factor. J Cell Physiol. 2005;204: 714-723.

[12] Wong BR, Rho J, Arron J, Robinson E, Orlinick J, Chao M, Kalachikov S, Cayani E, Bartlett FS, 3rd, Frankel WN, Lee SY, Choi Y. TRANCE is a novel ligand of the tumor necrosis factor receptor family that activates c-Jun N-terminal kinase in T cells. J Biol Chem. 1997;272:25190-25194.

[13] Lacey DL, Timms E, Tan HL, Kelley MJ, Dunstan CR, Burgess T, Elliott R, Colombero A, Elliott G, Scully S, Hsu H, Sullivan J, Hawkins N, Davy E, Capparelli C, Eli A, Qian YX, Kaufman S, Sarosi I, Shalhoub V, Senaldi G, Guo J, Delaney J, Boyle WJ. Osteoprotegerin ligand is a cytokine that regulates osteoclast differentiation and activation. Cell. 1998;93:165-176.

[14] Kiechl S, Werner P, Knoflach M, Furtner M, Willeit J, Schett G. The osteoprotegerin/RANK/RANKL system: a bone key to vascular disease. Expert Rev Cardiovasc Ther. 2006;4:801-811.

[15] Baud'huin M, Lamoureux F, Duplomb L, Redini F, Heymann D. RANKL, RANK, osteoprotegerin: key partners of osteoimmunology and vascular diseases. Cell Mol Life Sci. 2007;64:2334-2350.

[16] Collin-Osdoby P. Regulation of vascular calcification by osteoclast regulatory factors RANKL and osteoprotegerin. Circ Res. 2004;95:1046-1057.

[17] Hofbauer LC, Schoppet M. Clinical implications of the osteoprotegerin/RANKL/RANK system for bone and vascular diseases. Jama. 2004;292:490-495.

[18] Vega D, Maalouf NM, Sakhaee K. CLINICAL Review \#: the role of receptor activator of nuclear factor-kappaB (RANK)/RANK ligand/osteoprotegerin: clinical implications. J Clin Endocrinol Metab. 2007;92:4514-4521.

[19] Walsh MC, Choi Y. Biology of the TRANCE axis. Cytokine Growth Factor Rev. 2003;14:251-263.

[20] Montecucco F, Steffens S, Mach F. The immune response is involved in atherosclerotic plaque calcification: could the RANKL/RANK/OPG system be a marker of plaque instability? Clin Dev Immunol. 2007;2007:75805.

[21] Hofbauer LC, Schoppet M. Osteoprotegerin: a link between osteoporosis and arterial calcification? Lancet. 2001;358:257259.

[22] Min H, Morony S, Sarosi I, Dunstan CR, Capparelli C, Scully S, Van G, Kaufman S, Kostenuik PJ, Lacey DL, Boyle WJ, 
Simonet WS. Osteoprotegerin reverses osteoporosis by inhibiting endosteal osteoclasts and prevents vascular calcification by blocking a process resembling osteoclastogenesis. $J$ Exp Med. 2000;192:463-474.

[23] Price PA, June HH, Buckley JR, Williamson MK. Osteoprotegerin inhibits artery calcification induced by warfarin and by vitamin D. Arterioscler Thromb Vasc Biol. 2001;21:1610-1616.

[24] Morony S, Tintut Y, Zhang Z, Cattley RC, Van G, Dwyer D, Stolina M, Kostenuik PJ, Demer LL. Osteoprotegerin inhibits vascular calcification without affecting atherosclerosis in ldlr(-/-) mice. Circulation. 2008;117:411-420.

[25] Schoppet M, Sattler AM, Schaefer JR, Herzum M, Maisch B, Hofbauer LC. Increased osteoprotegerin serum levels in men with coronary artery disease. J Clin Endocrinol Metab. 2003; 88:1024-1028.

[26] Van Campenhout A, Golledge J. Osteoprotegerin, vascular calcification and atherosclerosis. Atherosclerosis. 2008.

[27] Dhore CR, Cleutjens JP, Lutgens E, Cleutjens KB, Geusens PP, Kitslaar PJ, Tordoir JH, Spronk HM, Vermeer C, Daemen MJ. Differential expression of bone matrix regulatory proteins in human atherosclerotic plaques. Arterioscler Thromb Vasc Biol. 2001;21:1998-2003.

[28] Sandberg WJ, Yndestad A, Oie E, Smith C, Ueland T, Ovchinnikova O, Robertson AK, Muller F, Semb AG, Scholz H, Andreassen AK, Gullestad L, Damas JK, Froland SS, Hansson GK, Halvorsen B, Aukrust P. Enhanced T-cell expression of RANK ligand in acute coronary syndrome: possible role in plaque destabilization. Arterioscler Thromb Vasc Biol. 2006;26:857-863.

[29] Kiechl S, Schett G, Schwaiger J, Seppi K, Eder P, Egger G, Santer P, Mayr A, Xu Q, Willeit J. Soluble receptor activator of nuclear factor-kappa B ligand and risk for cardiovascular disease. Circulation. 2007;116:385-391.

[30] Barreto FC, Barreto DV, Moyses RM, Neves CL, Jorgetti V, Draibe SA, Canziani ME, Carvalho AB. Osteoporosis in hemodialysis patients revisited by bone histomorphometry: a new insight into an old problem. Kidney Int. 2006;69:18521857.

[31] Coen G, Ballanti P, Balducci A, Calabria S, Fischer MS, Jankovic L, Manni M, Morosetti M, Moscaritolo E, Sardella D, Bonucci E. Serum osteoprotegerin and renal osteodystrophy. Nephrol Dial Transplant. 2002;17:233-238.

[32] Haas M, Leko-Mohr Z, Roschger P, Kletzmayr J, Schwarz C, Domenig C, Zsontsich T, Klaushofer K, Delling G, Oberbauer R. Osteoprotegerin and parathyroid hormone as markers of high-turnover osteodystrophy and decreased bone mineralization in hemodialysis patients. Am J Kidney Dis. 2002;39:580586.

[33] Grzegorzewska AE, Mlot M. Serum markers of bone turnover in dialyzed patients separated according to age. Int Urol Nephrol. 2006;38:311-316.

[34] Huang JC, Sakata T, Pfleger LL, Bencsik M, Halloran BP, Bikle DD, Nissenson RA. PTH differentially regulates expression of RANKL and OPG. J Bone Miner Res. 2004;19: 235-244.

[35] Nakashima A, Yorioka N, Doi S, Takasugi N, Shigemoto K, Kohno N. Osteoprotegerin and bone mineral density in hemodialysis patients. Osteoporos Int. 2006;17:841-846.

[36] Doumouchtsis KK, Kostakis AI, Doumouchtsis SK, Tziamalis MP, Tsigris C, Kostaki MA, Perrea DN. sRANKL/ osteoprotegerin complex and biochemical markers in a cohort of male and female hemodialysis patients. $J$ Endocrinol Invest. 2007;30:762-766.

[37] Kazama JJ, Shigematsu T, Yano K, Tsuda E, Miura M, Iwasaki Y, Kawaguchi Y, Gejyo F, Kurokawa K, Fukagawa M. Increased circulating levels of osteoclastogenesis inhibitory factor (osteoprotegerin) in patients with chronic renal failure. Am J Kidney Dis. 2002;39:525-532.
[38] Avbersek-Luznik I, Malesic I, Rus I, Marc J. Increased levels of osteoprotegerin in hemodialysis patients. Clin Chem Lab Med. 2002;40:1019-1023.

[39] Shaarawy M, Fathy SA, Mehany NL, Hindy OW. Circulating levels of osteoprotegerin and receptor activator of NF-kappaB ligand in patients with chronic renal failure. Clin Chem Lab Med. 2007;45:1498-1503.

[40] Avbersek-Luznik I, Balon BP, Rus I, Marc J. Increased bone resorption in HD patients: is it caused by elevated RANKL synthesis? Nephrol Dial Transplant. 2005;20:566570.

[41] Albalate M, de la Piedra C, Fernandez C, Lefort M, Santana $\mathrm{H}$, Hernando P, Hernandez J, Caramelo C. Association between phosphate removal and markers of bone turnover in haemodialysis patients. Nephrol Dial Transplant. 2006;21: 1626-1632.

[42] Nitta K, Akiba T, Uchida K, Kawashima A, Yumura W, Kabaya T, Nihei $H$. The progression of vascular calcification and serum osteoprotegerin levels in patients on long-term hemodialysis. Am J Kidney Dis. 2003;42:303-309.

[43] Kazama JJ, Kato H, Sato T, Shigematsu T, Fukagawa M, Iwasaki Y, Gejyo F. Circulating osteoprotegerin is not removed through haemodialysis membrane. Nephrol Dial Transplant. 2002;17:1860-1861.

[44] Yasuda H, Shima N, Nakagawa N, Mochizuki SI, Yano K, Fujise N, Sato Y, Goto M, Yamaguchi K, Kuriyama M, Kanno T, Murakami A, Tsuda E, Morinaga T, Higashio K. Identity of osteoclastogenesis inhibitory factor (OCIF) and osteoprotegerin (OPG): a mechanism by which OPG/OCIF inhibits osteoclastogenesis in vitro. Endocrinology. 1998;139:13291337.

[45] Sato T, Tominaga Y, Iwasaki Y, Kazama JJ, Shigematsu T, Inagaki H, Watanabe I, Katayama A, Haba T, Uchida K, Fukagawa M. Osteoprotegerin levels before and after renal transplantation. Am J Kidney Dis. 2001;38:S175-177.

[46] Irie A, Takami M, Kubo H, Sekino-Suzuki N, Kasahara K, Sanai Y. Heparin enhances osteoclastic bone resorption by inhibiting osteoprotegerin activity. Bone. 2007;41:165-174.

[47] Pettila V, Leinonen P, Markkola A, Hiilesmaa V, Kaaja R. Postpartum bone mineral density in women treated for thromboprophylaxis with unfractionated heparin or LMW heparin. Thromb Haemost. 2002;87:182-186.

[48] Vik A, Brodin E, Sveinbjornsson B, Hansen JB. Heparin induces mobilization of osteoprotegerin into the circulation. Thromb Haemost. 2007;98:148-154.

[49] Moe SM, Chen NX. Mechanisms of vascular calcification in chronic kidney disease. J Am Soc Nephrol. 2008;19:213-216.

[50] London GM, Guerin AP, Marchais SJ, Metivier F, Pannier B, Adda H. Arterial media calcification in end-stage renal disease: impact on all-cause and cardiovascular mortality. Nephrol Dial Transplant. 2003;18:1731-1740.

[51] Shroff RC, Shah V, Hiorns MP, Schoppet M, Hofbauer LC, Hawa G, Schurgers LJ, Singhal A, Merryweather I, Brogan P, Shanahan C, Deanfield J, Rees L. The circulating calcification inhibitors, fetuin-A and osteoprotegerin, but not Matrix Gla protein, are associated with vascular stiffness and calcification in children on dialysis. Nephrol Dial Transplant. 2008;23:3263-3271.

[52] Nitta K, Akiba T, Uchida K, Otsubo S, Takei T, Yumura W, Kabaya T, Nihei H. Serum osteoprotegerin levels and the extent of vascular calcification in haemodialysis patients. Nephrol Dial Transplant. 2004;19:1886-1889.

[53] Speer G, Fekete BC, El Hadj Othmane T, Szabo T, Egresits J, Fodor E, Kiss I, Logan AG, Nemcsik J, Szabo A, Nemeth ZK, Szathmari M, Tisler A. Serum osteoprotegerin level, carotidfemoral pulse wave velocity and cardiovascular survival in haemodialysis patients. Nephrol Dial Transplant. 2008;23: 3256-3262. 
[54] Morena M, Terrier N, Jaussent I, Leray-Moragues H, Chalabi L, Rivory JP, Maurice F, Delcourt C, Cristol JP, Canaud B, Dupuy AM. Plasma osteoprotegerin is associated with mortality in hemodialysis patients. J Am Soc Nephrol. 2006;17: 262-270.

[55] Schoppet M, Schaefer JR, Hofbauer LC. Low serum levels of soluble RANK ligand are associated with the presence of coronary artery disease in men. Circulation. 2003;107:e76; author reply e76.
[56] Yokoyama K, Shigematsu T, Miyaki K, Hara S, Ohkido I, Hosoya T, Kono T, Yoshida T, Muramatsu M. Low blood osteoprotegerin levels are a predictor to poor prognosis in Japanese patients on hemodialysis due to diabetic nephropathy. Ther Apher Dial. 2008;12:259-260.

Submitted: 15 January, 2009 Accepted after reviews: 5 March, 2009 